\title{
Use of Digital Economy Methods in Building Integrated Logistics Systems
}

\author{
Zinaida Khmelnitskaya ${ }^{1}$, and Elena Bogdanova ${ }^{1,2, *}$ \\ ${ }^{1}$ Ural State University of Economics, 620144 Yekaterinburg, Russia \\ ${ }^{2}$ Ural State University of Railway Transport, 6200034 Yekaterinburg, Russia
}

\begin{abstract}
The article deals with an actual problem: the use of digital economy methods in the construction of integrated logistics systems. The rationale for the need and feasibility of using digital technologies in creating integrated logistics is given. A methodological approach to the construction of integrated logistics using the digital blockchain method is proposed, the characteristic features of which in terms of the possibilities of its use are given by the authors.
\end{abstract}

\section{Introduction}

As part of the implementation of Decree of the President of the Russian Federation No. 204 of May 7, 2018 'on national goals and strategic objectives for the development of the Russian Federation for the period up to 2024', including with the aim of solving the problem of ensuring accelerated implementation of digital technologies in the economy and social sphere, the Government of the Russian Federation has formed the national program 'Digital economy of the Russian Federation' on the basis of the program 'Digital economy of the Russian Federation' approved by the minutes of the meeting of the Presidium of the presidential Council for strategic development and national projects dated June 4, 2019 No. 7.

The national program 'Digital economy of the Russian Federation' includes the following Federal projects approved by the minutes of the meeting of the Presidium of the Government Commission on digital development, use of information technologies to improve the quality of life and business conditions dated May 28, 2019 No. 9:

'Statutory regulation of the digital environment'

"Personnel for the digital economy"

'Information infrastructure'

'Information security'

'Digital technologies'

'Digital public administration' [1].

If we rely on the Federal law-149 'on Communications', we can say that the summary of information contained in databases and information technologies and technical means that ensure its processing is nothing more than an information system. The concept of digital

\footnotetext{
${ }^{*}$ Corresponding author: esbogdanova@rambler.ru
} 
economy, where one of the existing definitions treats this concept as a system of economic, social and cultural relations based on the use of information technologies. It is sometimes referred to as the Internet economy, the new economy, or the web economy.

The digital economy is based on the following information technologies: big data, neurotechnologies, artificial intelligence, distributed registry systems (blockchain), quantum technologies, new production technologies, industrial Internet, robotics, sensors, wireless communication, virtual and augmented reality [2]. The use of all the opportunities provided by digital economy technologies makes a change in organizational approaches and the functioning of logistics systems. For example, the distributed ledger technology (blockchain) has found its application in foreign trade transactions and the banking sector. The FINTECH enterprise, which embodies the ideas of the first legally pure blockchain in the Russian Federation, in addition to the Central Bank, included a whole galaxy of giants of the domestic market, represented by Sberbank of Russia, Alfa-Bank, OTKRITIE Bank, Tinkoff Bank, VTB [3]. The use of blockchain technology contributes to the implementation of logistics integration of both the systems themselves and information processes.

\section{Materials and Methods}

The introduction of integrated logistics systems is fundamental in solving a whole range of tasks in the socio-economic development of the country.

The authors agree with the definition of 'integrated logistics system', which was introduced by D. J. Bowersox in the 1980s and means that the integrated logistics system ensures the promotion of products through a continuous and consistent chain of step-by-step value addition with the purchase of goods and services at the right time, in the right quantity and form. The added value means that each side of the logistics system includes actions that increase the cost of the product or service for those who will receive the goods. At the same time, logistics can integrate distribution, production, and supply to synchronize rhythms and flows [4].

It is legitimate to believe that any production processes related to each other form a structure that makes it possible to develop and deliver high-quality products to the market at optimal prices and in the required time. When applying logistics systems to these processes, the entire logistics chain is combined, thereby forming the concept of logistics integration. In addition, since logistics acts as an apparatus for optimizing material flows and related flows (information, financial and service), these flows are now the object of study in this scientific direction [4].

The issues of information flow management in logistics, during the movement of material and other flows, were studied by the scientists: A. U. Albekov, B. A. Anikin, N. V. Afanasiev, G. L. Bagiev, A.M. Gadzhinsky, E. A. Golikov, M. P. Gordon, V. V. Dybskaya, M. E. Zalmanova, A.V. Zyryanov, O. N. Larin, N. A. Nagapetyants, Yu.M. Nerush, D. T. Novikov, O. A. Novikov, O. D. Protsenko, V. M. Purlik, V. I. Sergeev, V. G. Sankov, A. I. Semenenko, A. A. Smekhov, S. A. Uvarov, V. V. Shcherbakov, D. D. Bowersox, R. H. Ballow, D. D. Cross, W. Macmillan, J. Monden [5, 6].

The works of the Russian and foreign scientists: A. E. Brom, L. B. Mirotin, E. V. Pustynnikova, M. A. Betilgiriev, E. V. Sudov, A. I. Levin, A. N. Davydov, V. V. Barabanov, D. Bauersox, D. Kloss, D. Roy, W. Shapiro, J. M. William, A. Klasse [7, 8] are devoted to the construction of integrated logistics systems.

Highly appreciating the results of the research, it should be noted that the developments available in science and practice are quite distanced from the use of blockchain methods in solving issues of integration of logistics systems. At the same time, it is necessary to provide a number of reasoned statements that indicate the need and feasibility of digitalization of logistics systems: 
1. The significant amount of information at all levels of management activities of the enterprise;

2. The increase of product assortment, as well as tools and materials necessary for the production of finished products;

3. The use of information systems for transportation planning, inventory management, warehouse management, and other aspects of integrated logistics;

4. The processes of business globalization, the development of world trade blocs, which makes it more difficult to work in an integrated logistics environment;

5. The elimination of unnecessary intermediaries;

6. The presence of a large number of fake data, incorrect labeling of illegal goods and other types of fraud;

7. The ability to reduce the time for document management.

A striking example of the introduction of integrated logistics is the military-industrial complex of the United States, Japan, and Western European countries that are members of NATO. For example, L3 HARRIS.

It should be noted that the improvement of logistics operations is determined by success in the field of information technology. The development of information infrastructure contributes to the activation of commercial activities and increases competitiveness. The information flow resulting from the information support systems operation is formalized and presented in the form of specific, functional documents that form the document flow.

Currently, in the world there are information systems of integrated management systems MRP/MRPII, ERP, DBR, JIN and others.

According to the authors, the construction of integrated logistics systems requires the development of an algorithm that represents the general goal of the study and the tasks necessary for the implementation of this goal.

The study of domestic and foreign experience, as well as a number of practical studies in the construction of integrated logistics systems and corresponding information flows allowed the authors to develop a methodological approach to solving this problem. Based on the research goal - the choice and justification of digital economy methods in the construction of integrated logistics information systems, an algorithm for its step-by-step solution is proposed.

At the first stage, we generalize and study the progressive foreign and domestic experience in the application of blockchain technology in information logistics. The information obtained makes it possible to unify the capabilities of new operating models by using this technology.

The next stage is the creation of a working group whose tasks include the implementation of the entire complex of activities on the preparation of initial information for research and development of the current and strategic work plan.

Then a diagnostic analysis of the business processes of the integrated logistics system has to be performed. When identifying promising options for blockchain technology use, the possibility of its application has to be established, which is realistic if you receive a positive answer to the following questions:

- Is there a need for shared access to the database?

- How many parties (links) are involved in the logistics integration process?

- Is the security of information transmission provided during the processes?

- Is it possible to unify the process of information generalization in different functions? Are there any differences in the rules that govern the logistics processes of different participants?

- Is there a need for a consistent and unchangeable chain of records (data)?

- How often you need to change previously entered information?

The next stage is designing an integrated logistics information system. 
The final stage is the process of testing this method in practice.

A list of all possible participants in the new integrated logistics system has to be formed. These can be internal services of the company, outsourcing companies, as well as other external partners, such as customs, banks, insurance companies, and others. The technical task for creating an information system has to be developed. Then, partnerships are established with potential external participants and organizational and legal forms of interaction are formed.

Next, based on the terms of reference and budget, a trial information product is created, which is tested on small amounts of links and information.

Having received positive tests and implemented a pilot project on small amounts of information, the product is scaled to all participants of the integrated system engaged in all operations of the information flow.

Then handling of the information product is done, as well as possible expansion and addition of a bigger number of participants into the system.

The practical implementation of the proposed methodological approach for building integrated logistics systems using blockchain technology has been tested in the conditions of enterprises and is reflected in the work of the authors [9].

The stages of research can be combined to some extent, but the contours of information are highlighted and optimized only when the structure of the system and its functions are considered and optimized.

\section{Results and Discussion}

The validity of the methodological approach proposed by the authors to the use of blockchain technology in the digitization of integrated logistics systems was confirmed by its testing in the conditions of SVX Logistics LLC and Direct-Express LLC[9].

Blockchain technology enables to create distributed applications on its basis, the code of which is implemented on the computers of network participants. With the help of blockchain, the company has the opportunity to organize a secure supply chain. Each product receives a specific label that allowed the company to protect its supply chains with software products.

A single level of access allows companies to synchronize system updates in real time and change data using one interface without affecting other systems. Thus, all the necessary information can be concentrated on personal equipment that is easy to access. This makes the supply chain completely transparent, which allows to draw up contracts in the form of a code protecting against human factors and violations of documentation rules. This approach allows ensuring the reliability and availability of information for all participants in the process.

The results of the work were discussed at the meeting of the working group, where points of view were expressed in favor of this project, which is presented in the section results and conclusion. However, the discussion was focused on the release of labor and training of personnel who can successfully perform the functions that will put the proposed work in the context of digitalization of integrated logistics systems. The next question, which is also somewhat problematic. This is an opportunity to quickly respond to all parts of the production process involved in possible force majeure circumstances.

\section{Conclusions}

Currently, the blockchain technology is going beyond the use of cryptocurrencies and will soon spread its influence to all sectors of the economy. The authors believe that in the logistics sector, the technology will significantly improve the efficiency of business processes, bring new innovative services to the market, and form new business models. 
Having studied the data on practical developments that are currently being conducted by the largest international logistics companies, TRANS-national corporations together with IT developers in the field of blockchain, we can conclude that the formation of a global logistics is beginning, its efficiency is achieved by increasing the transparency of supply chains, data transfer speed and automation of administrative processes.

In addition, the blockchain technology allows you to create distributed applications on its basis, the code of which is implemented on the computers of network participants. With the help of blockchain, companies can organize a secure supply chain. Each product gets a specific label, which allows companies to protect their supply chains using software products. A unified register makes it possible to store information about the authenticity of raw materials, origin, security certificates, storage location, and records. A single level of access allows companies to synchronize system updates in real time and change data using one interface without affecting other systems. This way, all the necessary information is stored in one place that is easy to access, making the supply chain completely transparent. This enables to create contracts in the form of executable code that is protected from human factors and violations of the rules. This approach will ensure the reliability and availability of information for all participants at any time[10].

\section{References}

1. National program "Digital Economy of the Russian Federation" Minutes No. 7 of the meeting of the Presidium of the Council under the President of the Russian Federation for Strategic Development and National Projects of June 4 (2019)

2. V. Trofimov, Izvestia SPbSEU, 4, 105 (2019)

3. D.A. Zakoldaev, R.V. Yamshchikov, N.V. Yamschikova, Bulletin of the Moscow State Regional University, 2, 93 (2018)

4. D.I. Panferov, Planning and Economic Department, 6, 7 (2011)

5. O. N. Larin, Transport: science, technology, management, 9, 37 (2019)

6. E.V. Pustynnikova, Integrated logistics (2017)

7. V.A. Gudkov, L.B. Mirotin, S.A. Shiryaev, D.V. Gudkov, Basics of Logistics: Textbook for Universities (2004)

8. L.B. Mirotin, Fundamentals of Logistics (1999)

9. Z. Khmelnitskaya, E. Bogdanova, M. Ivich, Building logistic information systems using the blockchain digital economy method, Published in Proceedings of the International Scientific and Practical Conference on Digital Economy (ISCDE) on November 07 (2019)

10. E.S. Bogdanova, Logistics 4.0: Breakthrough through the development of infocommunication technologies, Technological Initiatives and Achievement of Sustainable Development Goals: Proceedings of the International Scientific and Practical Conference, XV South Russian Logistics Forum October 10-11 (2019) 